\title{
Sustainable use of electrical energy at the University of Sonora, Mexico
}

\author{
N. Munguía, ${ }^{1 *}$ A. Zavala ${ }^{1}$, L. Velázquez ${ }^{12}$ \\ 1. Industrial Engineering Department, University of Sonora, México \\ 2. Work Environment Department, University of Massachusetts Lowell \\ *Corresponding author.Tel/Fax +52 662 2516574, email nmunguia@industrial.uson.mx
}

\begin{abstract}
The University of Sonora as a sustainable higher education institution has been committed for almost two decades to continuously increase its involvement with society by helping in their transition to more sustainable lifestyle and recently by implementing and maintaining a Sustainability Management System (SMS) on Campus which it is actually certified under the ISO 14001:2004 international standard. One of the sustainability programs within the SMS is the Sustainable Management of Electrical Energy (SMEE) that comprises not only energy efficiency initiatives but also energy conservation initiatives. This paper is aimed at describing the experience of the University of Sonora in fostering changes on attitudes and behaviors that result in energy conservation. Before the implementation of the SMEE was common to find lack of interest among students, professor, and employees for energy conservation behaviors such as shutting down air conditioners or turning off lights when they were not necessary given as a result a repeatedly energy wastage and consequently, the generation of CO2 emissions that increase climate change. Findings presented in this paper indicate that changes on attitudes and behaviors can generate good practices for conserving energy and reduce the environmental burden of universities. Sustainability indicators have proven the efficacy and efficient of the SMEE; at the financial dimension, the SMEE has reached savings of over 5, 840 USD in three years; from the environmental dimension, the SMEE has avoided the emissions of 33,287 $\mathrm{kg}$ of $\mathrm{CO} 2$, but the most important indicator come from the social dimension where wasting behaviors have been modified by increasing community awareness. Positive trends on the SMEE indicators suggest the increasing of awareness of the impact of energy wastage among the university community who act in consequence of this in favor of the environment. Additionally, an awareness survey was conducted to 650 members of the university community such as faculty, students, administrative staff and service personnel to reveal which energy conservation initiatives would be willing to follow, such as: turn off the lights at the term class, turn off the air conditioned when the classroom is not in use, close doors and windows to avoid that the air-conditioning air leakage, etc. Findings show that most of participants are becoming aware of the impact of the energy wastage and they are willing to participate in the SMEE in order to reduce those environmental impacts. Findings also show that willingness of the university community for participating or supporting more than one energy conservation initiatives on campus; the behavior of turn off lights and air conditioners when finishing the class is the preferred option.
\end{abstract}

Keywords: Energy conservation, Sustainable management system, Climate change

\section{Introduction}

The dependence of petroleum and coal has had terrible consequences for the planet, such as global warming, pollution, and the dependency of some countries over other countries [1]. On global scale, climate change has raised lots of concerns; international initiatives such as the UN Framework Convention on Climate Change have raised alertness about the role of energy in human's impacts reflecting on the environment and the same manner effecting for sustainable development [2]. There is no doubt that human activities alter the climate mainly where CO2 is emitted to the atmosphere producing the greenhouse effect [3]. Clearly, this situation has forced individuals and organizations to put into practice efforts to reduce energy consumption and in particular energy wastage. According to EPA, opportunities for energy conservation are increasingly available in almost every application in any setting such as homes, schools, offices, and industrial environments [4]. 
The University of Sonora in its intent to become a more sustainable higher education institution has been committed for almost two decades to energy conservation by implementing and maintaining a Sustainability Management System (SMS) on Campus [5].

After more than 5 years of its implementation, the SMS succeed, in July 2008, an ISO 14001:2004 external audit and as a consequence it got the ISO certification; two years later, the SMS was challenged again by two follow-up audits that were conducted and approved with success. So far, this accomplishment has not been mirrored by any other public university in Latin-America.

The goal of the SMS is the protection of natural resources and the prevention, reduction and/or elimination of environmental and occupational risks generated by the members of the university community when using resources in order to carry out its substantive functions of teaching, research, outreach \& partnership, and stewardship.

One of the sustainability programs within the SGS is the Sustainable Management of Electrical Energy (SMEE) that comprises not only energy efficiency initiatives but also energy conservation initiatives with the purpose of reducing energy consumption and in particular, energy wastage. For the University of Sonora, energy conservation is related to human behavior; therefore, the SMEE strives to changes negative lifestyles of its community.

Before the implementation of the SMEE was common to find lack of interest to energy conservation initiatives among students, professor, and employees; hence, electrical bills and CO2 emissions were out of control; however, this situation has gradually changed.

Under this context, this paper is going to be aimed at describing the experience of the University of Sonora in fostering changes on attitudes and behaviors that result in energy conservation.

\section{Methodology}

The Sustainable Management of Electrical Energy (SMEE) Program has several steps that work integrated to reach the strategic objective of changing of attitudes and behaviors and energy efficiency initiatives. These steps can be summarized as follows:

\subsection{SMS Scope}

The scope of the SMS is the engineering college; this means that energy conservation efforts are focused on facilities within this college. The engineering college is located at block five of the campus which includes eleven typical buildings of a higher education institution such as classrooms, laboratories, and administrative offices.

\subsection{Inventory of electrical equipment and accessories}

Commonly, energy is used in lighting, computers and peripherals; science equipment and office devices. The inventory of electrical equipment and accessories is conducted annually and involves not only the accounting but also the physical shapes of equipment and installations within the scope of the Sustainability Management System (SMS). The minimum information required by equipment and / or accessory is their power consumption on watt, or its equivalent, as well as their physical condition at the time of conducting the inventory. 


\subsection{Monitoring procedure.}

The monitoring procedure is intended to verify if the electricity is being used efficiently and rationally by the university community. This procedure is done each day, but reporting is on a weekly basis; this consists on certain number of visits made by the reviewers assigned to specific areas in buildings to record if there is a waste of energy. Each wasteful behavior is considering a failure and, if it is possible, interventions on situ must be conducted to timely eliminate and / or reduce energy wastage.

\subsection{Indicators}

Sustainable indicators are calculated based on weekly records. There are several factors to consider for measuring performance. Wastages are expressed in financial, environmental, and power metrics. Indicators from 2008 to 2010 are shown in tables 2 to table 4 .

\subsection{Dissemination of information}

Increasing energy conservation awareness among the university member is imperative in order to reduce energy wastage behaviors. A key requirement of the SMS is the divulgation of indicators on a quarterly basis. This is done throughout flyers, brochures, and emails.

\subsection{Sustainability Management System (SMS) Survey}

A survey was conducted to faculty members, students, administrative staff and service personnel to indicate which energy conservation initiatives would be willing to follow, such as: turn off the lights at the term class, turn off the air conditioned when the classroom is not in use, close doors and windows to avoid that the air-conditioning air leakage, etc. The surveys were applied to 650 members of the university community. The selection of individuals was selected by a simple random sampling method. The sampling Eq. (1) is following showed:

$n=\frac{Z^{2} p q N}{\mathrm{NE}^{2}+\mathrm{Z}^{2} \mathrm{pq}}$

Where $\mathrm{n}$ is the sampling size, $\mathrm{Z}$ is confidence level, $\mathrm{p}$ is positive variation, $\mathrm{q}$ is negative variation and $\mathrm{N}$ is population size.

\section{Results}

\subsection{Awareness Survey}

The results of the SMS survey are presented in Table 1. In general, most of participants are becoming aware of the impact of the energy wastage and they are willing to participate in the SMEE in order to reduce those environmental impacts. Findings also show that willingness of the university community for participating or supporting more than one energy conservation initiatives; the behavior of turn off lights and air conditioners when finishing the class is the preferred option. 
Table 1 Awareness survey

\begin{tabular}{|c|c|c|}
\hline Item & Yes & No \\
\hline Support the SMS & 75 & 25 \\
\hline Energy Wastage & 70 & 30 \\
\hline Awareness & & \\
\hline $\begin{array}{l}\text { Willingness to } \\
\text { participate in the } \\
\text { SMEE }\end{array}$ & 90 & 10 \\
\hline $\begin{array}{l}\text { Participation on } \\
\text { more than one } \\
\text { initiative }\end{array}$ & 95 & 5 \\
\hline $\begin{array}{l}\text { Turn off the lights/ } \\
\text { classrooms/room }\end{array}$ & 38 & 62 \\
\hline Turn off the AC & 35 & 65 \\
\hline $\begin{array}{l}\text { Closing door or } \\
\text { window/ AC }\end{array}$ & 18 & 82 \\
\hline $\begin{array}{l}\text { Turn off the PC } \\
\text { Monitor }\end{array}$ & 9 & 91 \\
\hline
\end{tabular}

\subsection{Calculations of electrical energy metrics}

Table 2 shows the monitoring records for 2008, there were recorded 1759 energy wastage events, denominated failures; however; it was possible to intervene an avoid the impacts associated with in 882 out of those 1759. Thank to these interventions, there were avoided the wastage of 10,188 kw; and consequently, the emissions of $9271 \mathrm{~kg}$ of CO2. In monetary terms, savings were 1,626 USD.

Table 2. 2008 Sustainability Indicators

\begin{tabular}{lcc}
\multicolumn{1}{c}{ Indicator } & Units & Amount \\
\hline Failures & events & 1759 \\
Interventions & events & 882 \\
Avoided Energy Wastage & $\mathrm{kw}$ & 10,188 \\
& & \\
Avoided CO2 emissions & $\mathrm{kg}$ & 9271 \\
*Savings & $\mathrm{USD}$ & 1,626 \\
& & \\
\hline
\end{tabular}

* Exchange rate: US\$ $1.00=$ MX\$ 12.53 at December 14, 2010.

Source: Banco Nacional de México, S.A.

Records for the entire 2009 are shown in Table 3. During this year, there were 446 interventions that avoided the wastage of 11,579 kw and the emissions of $1265.63 \mathrm{~kg}$ of CO2. This represented a saving of 1,848 dollars for the institution. 
Table 3. 2009 Sustainability Indicators

\begin{tabular}{lcc}
\multicolumn{1}{c}{ Indicator } & Units & Amount \\
\hline Failures & events & 2,322 \\
Interventions & events & 756 \\
Avoided Energy Wastage & $\mathrm{kw}$ & 11,579 \\
& & \\
Avoided CO2 emissions & $\mathrm{kg}$ & 10,536 \\
$*$ Savings & USD & 1,848 \\
& & \\
\hline
\end{tabular}

* Exchange rate: US\$ 1.00 = MX\$ 12.53 at December 14, 2010.

Source: Banco Nacional de México, S.A.

Table 4 shows records for 2010; the energy wastage avoided was 14,812 kw that represents $13,479 \mathrm{~kg}$ of CO2. Figure 1 illustrates the 2008-2010 trend of each indicator; it is possible observe on it the improvements per year of each indicator which suggest that SMEE is fulfilling its goal.

Table 4. 2010 Sustainability Indicators

\begin{tabular}{lcc}
\hline \multicolumn{1}{c}{ Indicator } & Units & Amount \\
\hline Failures & events & 3,467 \\
Interventions & events & 936 \\
Avoided Energy Wastage & $\mathrm{kw}$ & 14,812 \\
& & \\
Avoided CO2 emissions & $\mathrm{kg}$ & 13,479 \\
$*$ Savings & $\mathrm{USD}$ & 2,364 \\
& & \\
\hline
\end{tabular}

* Exchange rate: US\$ 1.00 = MX\$ 12.53 at December 14, 2010.

Source: Banco Nacional de México, S.A.

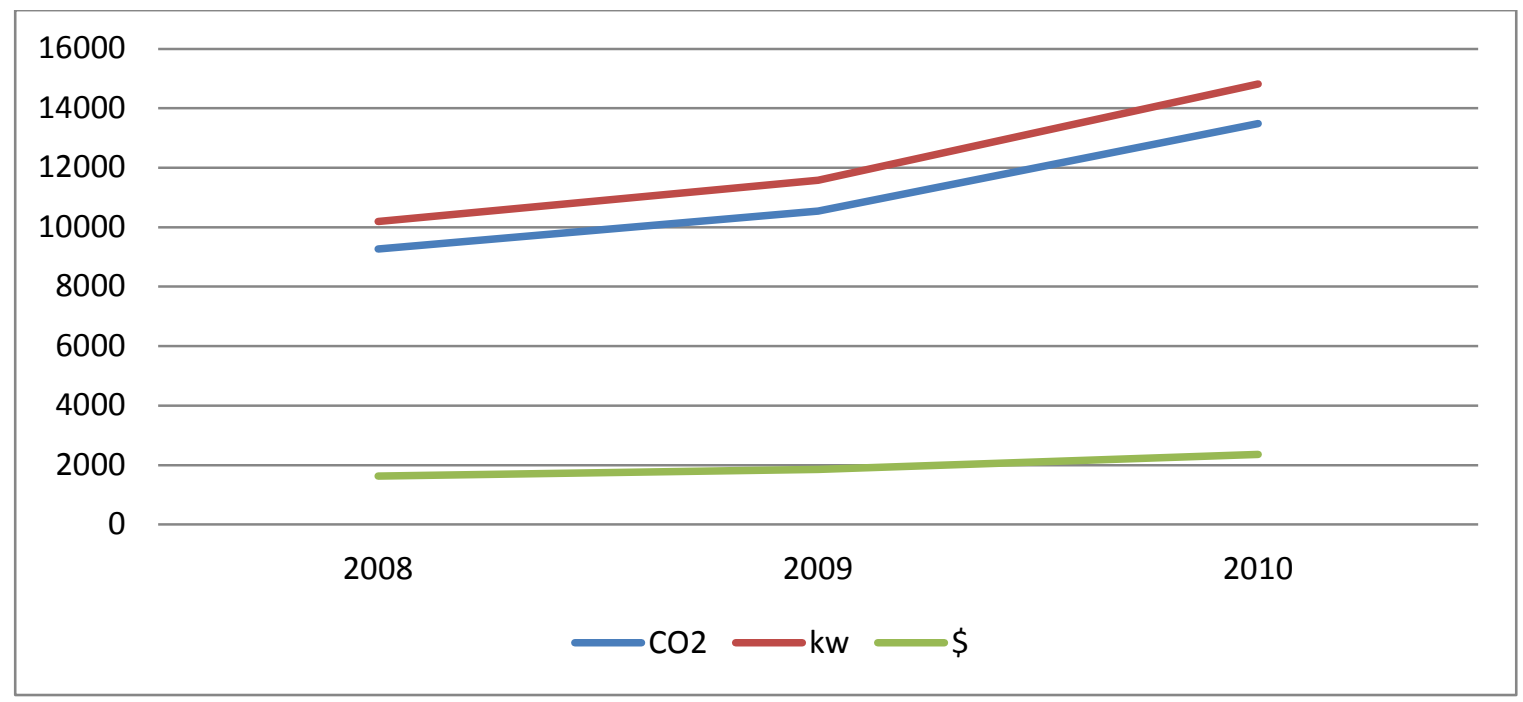

Fig 1. Sustainability Indicators Trend 


\section{Conclusion}

The University of Sonora, through initiatives like the Sustainable Management of Electrical Energy (SMEE) Program, shows that it is possible for universities to reach important economic, social and environmental outcomes.

Findings presented in this paper indicate that changes on attitudes and behaviors can generate good practices for conserving energy and reduce the environmental burden of universities.

Sustainability indicators have proven the efficacy and efficient of the SMEE; at the financial dimension, the SMEE has reached savings of over 5, 840 USD in three years; from the environmental dimension, the SMEE has avoided the emissions of 33,287 $\mathrm{kg}$ of $\mathrm{CO} 2$, but the most important indicator come from the social dimension where wasting behaviors have been modified by increasing community awareness. Positive trends on the SMEE indicators suggest the increasing of awareness of the impact of energy wastage among the university community who act in consequence of this in favor of the environment.

Result from the 2010 survey indicated the willingness of the community to support and fully commitment to the SMS and in particular with the SMEE.

Become a more sustainable university is a hard task that cannot achieve without the participation of the community, mainly students; they need to get a better understanding of human health exposures and environmental impacts generated because energy wastage.

Turning off lights when the classrooms are not being used or by closing doors when the air conditioned equipment is in use, it can be very helpful for sustainability on campus; yet, before the operation of the SMEE, these events were very common in university lifestyle. Although today those practices still are present, they are not the common denominator. It is clear that the path to sustainability is full of obstacles; yet, there is no other way.

\section{References}

[1] D. Aerts, B. True, Energy Conservation and Renewable Energy in Homes, Journal of Chemical Education Vol. 83, No. 10, 2006, pp 1440-1443

[2] B. Gallachoir, M. Keane, E. Morrissey, E. O’Donnell, Energy and Buildings 39, 2007, pp. 913-922

[3] W. Burroughs, Climate Change: A multidisciplinary Approach, Second Edition, 2007, Cambridge University Press, ISBN 978-0-521-87015-3.

[4] Environmental Protection Agency 2010. On line: January 25, 2011 Available at:

(http://www.epa.gov/greenkit/q5_energ.htm).

[5] L.Velazquez, N. Munguia, J. Esquer, et. al., Sustainability leadership by implementing the ISO 14001 framework on a Latin-American Campus, in book Sustainability at Universitiesopportunities, challenges and trends, Peter Lang , 2009, vol. 31, pp. 207-224

[6] Banco Nacional de México (2010). Online: December 12, 2010. http://www.banamex.com/ 